\title{
Tectono-geochemistry weak information extraction and its application
}

\author{
SONGTAO Li ${ }^{1,2}$, JiANZHONG LiU ${ }^{2,3 *}$, ZEPENG WANG ${ }^{1,2}$, QINPING TAN ${ }^{4}$, LIANGYI Xu ${ }^{1}$, ChENGFU YANG ${ }^{1,2}$

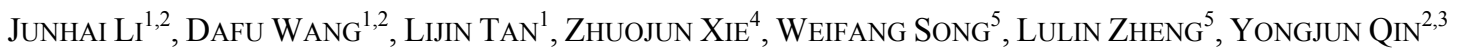

1.Geological Party 105, Guizhou Provincial Bureau of Geology and Mineral Exploration \& Development, Guiyang 550018, China (lisongtaozgh@163.com)

2.Technical Innovation Center of Mineral Resources Exploration Engineering in Bedrock Area and Natural Resources, Guiyang 550081, Guizhou ,China

3.Bureau of Geology and Mineral Exploration and Development Guizhou Province, Guiyang 550004, China (*correspondence: 2585364825@qq.com)

4.Institute of Geochemistry, Chinese Academy of Sciences, Guiyang 550081, China

5.Guizhou University, Guiyang 550002, China

The cover thickness is relatively large where exploration work has not yet been carried out in southwestern Guizhou. In addition, the shallow geochemical anomalies from deep concealed Carlin-type orebodies must be very weak. How to extract weak metallogenic information in the surface is the key to finding concealed deposits. In recent years, some scholars have tried to use tectonic-geochemistry to extract deep weak mineralization information in the area (Liu Jianzhong et al., 2016).

Theoretical basis of the tectono-geochemistry weak information extraction: tectonic zones, faults, joints, and fractures definitely have high permeability, probably connect to deep mineralization systems and act as channels that ore-bearing hydrothermal fluids vertically migrate from deep to surface. The channels inevitably leave more or less tracks of gas-liquid activities. The tracks (refer as tectono-geochemical anomalies) are recorded by tectonites, fillings in faults, joints and fracture, and altered rocks, which contain higher content of ore-related elements or special isotopic compositions compared with wall rocks. The tectono-geochemistry anomalies are usually obvious and show large gradient, and can effectively reveal deep metallogenic informations and contribute to prospecting prediction of deep concealed deposits.

Objective: discovering deep metallogenic information judged by whether there are tectono-geochemistry anomalies. Premise: indepth studies of deposit types, metallogenic models, orebody geometry, and ore-forming element assemblages of typical deposits in certain region. Sampling principle: samples are only collectted from tectonic zones, faults, joints, and fractures, otherwise no sampling. Sampling media: tectonites, fillings in faults, joints and fracture, and altered rocks. Sampling grid: sampling grid is roughly $100 \times 40 \mathrm{~m}$, but it does't need to rigidly adhere to the fixed grid of traditional geochemical exploration. Samples are collected within $20 \mathrm{~m}$ around designed sampling grid point. Multiple samples can be collected near a single designed point as for a complex tectonic assemblage. While, if there are no any tectonic zones, faults, joints, fractures, and altered rock near a designed sampling point, this point can be discarded. Sample analysis: the compositions of ore-forming element assemblages need to be analyzed (Liu Jianzhong et al., 2017, Yuan Shunfa, 2018).

a comparative case study of 1:50000 soil geochemistry survey and 1:50000 and 1:10000 tectono-geochemistry weak information extraction were carried out at the Baogudi Carlin-type Au district, Southwest Guizhou, China. The results show that (1) the anomalies have good reproducibility bewteen the soil geochemistry survey and the tectono-geochemistry weak information extraction. (2) More details and larger anomalous areas were delineated by the tectono-geochemistry weak information extraction compared to soil geochemistry survey. The tectono-geochemistry weak information extraction can obviously magnify and strengthen "high", "large", and "complete" geochemistry anomalies. (3) The highest content of Au obtained from the tectono-geochemistry weak information extraction is ten times higher than that of the soil geochemistry survey. (4) The tectono-geochemistry weak information extraction can delineate geochemistry anomalies where show no any anomalies based on soil geochemical survey, indicating that this method is useful to reveal weak mineralization information and to discover concealed deposits. (5) The tectono-geochemistry weak information extraction is efficient and low-cost because the sample quantity is only $60 \%$ of the soil geochemistry survey.

Applications of the tectono geochemistry weak information extraction have been widely conducted to prospect buried Carlin-type Au deposits in southwestern Guizhou, China, and numbers of prospecting targets, Au occurrences and deposits have been discovered. The continuous improvement and maturity of the tectono geochemistry weak information extraction are expected to play a more and more important role in prospecting of concealed Carlin type gold deposits in southwestern Guizhou, and to provide key geochemical support for constructing Nanpanjiang-Youjiang "1000-tons" gold resource base.

References: omitted.

Fund projects: National Science Foundation of China (No: U1812405), National Key R\&D Program of Deep Mineral Resources Exploration and Exploitation (No:2017YFC0601500) 